\title{
Feasibility of Weekly Cisplatin Versus Gemcitabine Concomitant with Radiation in The Management of Locally Advanced Carcinoma Cervix
}

\author{
Authors \\ Vani Singh ${ }^{1}$, S K Singh², J K Singh ${ }^{3}$, Bhaskar Shahbabu ${ }^{4}$, Richa Chauhan ${ }^{5}$, \\ Anamika Kumari6 \\ ${ }^{1}$ Senior Resident (Dept. of Radiotherapy), RIMS, Ranchi, India \\ ${ }^{2}$ Lt Col. (Classified Specialist Internal Medicine), Dept of Medicine and Pulmonary Medicine, \\ MH Namkum, India \\ ${ }^{3}$ Director, S S Hospital\& Research Centre and Former Director, Mahavir Cancer Sansthan, Patna \\ ${ }^{4}$ Captain, Medical Officer (Preventive and Social Medicine Specialist) \\ ${ }^{5}$ Radiation Oncologist, Mahavir Cancer Sansthan, Patna \\ ${ }^{6}$ Radiation Oncologist, Raj Hospital, Ranchi \\ Corresponding Author \\ Santosh Kumar Singh \\ Lt Col. (Classified Specialist Internal Medicine), Dept of Medicine and Pulmonary Medicine, \\ MH Namkum, India \\ Email: sksingh77@ rediffmail.com
}

\begin{abstract}
Introduction: Cervical cancer is the fourth most common malignancy in women worldwide (1). The study was conducted to evaluate the feasibility, toxicity and response of weekly gemcitabine against the widely accepted weekly cisplatin with concurrent conventional radiotherapy in management of locally advanced cervical cancer.

Methodology: A prospective randomized control study was done with 25 patients of carcinoma cervix in each arm of Gemcitabine (Group A) and Cisplatin (Group B) based concurrent chemoradiotherapy. Pretreatment and Post-treatment assessment was done to assess the efficacy and toxicity profile of the patients.

Results: External beam radiation as per protocol was completed by 60\% in Group A and 68\% in Group B. $52 \%$ patients in group $A$ and $60 \%$ in group B completed the treatment in less than 55 days. Acute toxicities were responsible for $20 \%$ of the delay in-group $A$ and $16 \%$ of group B. Late toxicities were mild to moderate. Overall complete response was seen in $83.3 \%$ of patients in-group A and $80 \%$ patients in-group B. Locoregional control was seen in $79.2 \%$ of the patients of group A and $76 \%$ of patients of group B. Locoregional failure was seen in $12.5 \%$ patients of group $A$ and $12 \%$ patients of group B. $4.17 \%$ patients in group $A$ and $8 \%$ patients in group B had distant metastases.

Conclusion: Gemcitabine can be a better alternative to Cisplatin considering its easy administration, similar disease control and toxicity profile.

Keywords: Cervical Cancer, Gemcitabine, Cisplatin, Chemoradiotherapy,
\end{abstract}

\section{Introduction}

Cervical cancer is the fourth most common malignancy in women worldwide ${ }^{(1)}$. More than $85 \%$ of the global burden occurs in the developing countries where it accounts for $12 \%$ of all female cancers ${ }^{(1)}$. In India, cervical cancer is ranked as the 
most common cancer in women ${ }^{(2)}$. The incidence of cervical cancer in India is $26.2 \%$ and mortality is $14.7 \%$ per 100,000 woman ${ }^{(2)}$. Thus India accounts for, $27 \%$ of new cervical cancer cases and $27 \%$ death due to cervical cancer in the world ${ }^{(2)}$. The key to reducing cervical cancer morbidity and mortality is early detection by screening coupled with timely treatment of precancerous lesions ${ }^{(3)}$. Concurrent chemoradiation therapy is being tested for many years with an attempt to improve treatment results.Studies demonstrated that survival rate with concomitant chemotherapy $(\mathrm{CT}+\mathrm{RT})$ based on cisplatin was superior than that obtained with radiation alone ${ }^{(4,5)}$. Over the years, a number of other chemotherapeutic agents have been tried either alone or in combination eg Hydroxyurea, 5Fluorouracil, Mitomycin C, Gemcitabine and Paclitaxel. Gemcitabine, (2',2'-difluorodeoxycytidine) is a very potent and specific deoxycytidine analogue ${ }^{(6)}$. Gemcitabine is a known radiosensitizer and has been used in a wide variety of human cancer cell lines ${ }^{(6)}$. Various studies have reported that Gemcitabine is highly synergistic to radiation in cervical cancer cell lines ${ }^{(7)}$. Several trials were performed with Gemcitabine as radiosensitiser ${ }^{(8,9)}$. Inspired by these results, the present study was conducted to evaluate the feasibility, toxicity and response of concurrent weekly gemcitabine against the widely accepted concurrent weekly cisplatin with standard conventional radiotherapy in management of locally advanced cervical cancer.

\section{Methodology}

This prospective randomized study was carried out in Department of Radiotherapy in a tertiary care oncology center in Eastern India. Considering the feasibility, it was decided a minimum of 25 patients randomized in each arm of the study. The study period was from June 2013 to May 2015, a minimum follow-up of six months was required. All the patients were previously untreated.

Selection of Cases: Patients with carcinoma cervix referred to Department of Radiotherapy, satisfying the below listed eligibility criteria were recruited in the study.

\section{Inclusion criteria}

1. Carcinoma of the uterine cervix, clinical stage IIIB (FIGO stage)(10).

2. Biopsy proved squamous cell carcinoma.

3. No evidence of metastatic disease.

4. Age between 18 to 65 years.

5. Karnofsky Performance Status $\geq 70(11)$.

6. Normal chest $\mathrm{x}$-ray

7. Haematology, renal and hepatic functions as follows: $(\mathrm{Hb} \geq 10 \mathrm{gm} / \mathrm{dl}, \quad \mathrm{TLC} \geq 4000 / \mathrm{mm} 3$, Platelet count $\geq 1,00,000 / \mathrm{mm} 3$, Serum creatinine $\leq 1.5$ times the normal upper limit, Serum bilirubin $\leq 1.5$ times the normal upper limit).

\section{Exclusion criteria}

1. Poor general condition with Karnofsky Performance Status < 70 (11)

2. History of prior radiotherapy or chemotherapy

3. Pregnancy

4. Patients with histology other than squamous cell carcinoma

5. Age less than 18 years or more than 65 years.

6. Metastatic disease.

7. Presence of Fistulas

\section{Randomization to Groups}

After patient signed the consent form she was randomized into either group A or Group B by odd $\&$ even method. Odd numbered patient were kept in - group A and even numbered in group B.

- Group A -Radiotherapy + Gemcitabine.

- Group B -Radiotherapy + cisplatin.

Pre-Treatment Work Up: After taking a thorough history patients were staged clinically according to the International Federation of Gynecologists and Oncologists (FIGO) staging system ${ }^{(10)}$. A through clinical examination was performed including perspeculum examination, per-vaginal examination, digital rectal examination, and per-abdominal examination. A biopsy was done in every case. The pre-treatment work up included complete blood count, kidney function tests, liver function tests, serum electrolytes, chest x-ray PA view (CXR), ultrasound (USG) abdomen and pelvis. Contrast enhanced computed tomography (CECT) scan of 
abdomen and pelvis, Cystoscopy and proctosigmoidoscopy were done as required.

\section{Treatment Protocol}

1. Radiotherapy: The conventional pelvic radiotherapy was planned in Co-60 unit to the whole pelvis by parallel-opposed anterior-posterior portals with SAD technique. Midline shield was not done. Upper, lateral and lower borders of the anterior and posterior pelvic fields were at L4-L5 inter-vertebral space, 1.5 to $2 \mathrm{~cm}$ lateral to the widest bony pelvic wall and inferior border of obturator foramen. Antero posterior diameter was determined by calliper, placed at the centre of radiation field. Delivered dose was $50 \mathrm{~Gy}$ in 5 weeks/5 fractions per week. It was followed by 3 sessions of highdose-rate (HDR)-brachytherapy started within 3 to 5 days.

The dose given per fraction was 6-7Gy depending upon the bladder and rectal dose with a gap of one week between each session. The overall treatment time was 56-60 days.

Radiotherapy was delivered within 4 to 6 hours of chemotherapy administration.

2. Chemotherapy: Concurrent chemotherapy commenced within the first 3 days of starting of radiotherapy.

Group A - Patients in the gemcitabine arm received conventional radiotherapy with concurrent gemcitabine $150 \mathrm{mg} / \mathrm{m} 2$ weekly as intravenous infusion. Premedication with Ranitidine 50mg, Dexamethasone $8 \mathrm{mg}$, Ondansetron $8 \mathrm{mg}$ intravenous push was given before Gemcitabine infusion. Gemcitabine was diluted in $150 \mathrm{ml}$ Normal Saline and infused over 30 minutes.

Group B - Patients in the cisplatin arm received conventional radiotherapy with concurrent cisplatin $40 \mathrm{mg} / \mathrm{m} 2$ weekly as intravenous infusion. Premedication with ondansetron $8 \mathrm{mg}$ intravenous push and hydration with one liter of Normal Saline was given.one ampule of KCL was given before cisplatin. Cisplatin was diluted in $500 \mathrm{ml}$ of Normal Saline and infused at a rate of $1 \mathrm{mg} / \mathrm{minute}$. Following cisplatin infusion $300 \mathrm{ml}$ of $20 \%$ Mannitol and one liter of Normal Saline with $1 \mathrm{gm}$ of magnesium sulphate was infused. Patients were advised to take oral antiemetics for 3 days.
Chemotherapy was withheld in patients who developed grade 3 lower gastrointestinal toxicity, Haemoglobin $<8$ gm/dl, leukocyte count $<3,000$ cell $/ \mu 1$, thrombocytopenia $<100 \times 103 / \mu 1$, and patients with rising liver function tests. Acute radiation toxicities were defined as occurring during radiotherapy and within 90days after it's completion and Late toxicities as occurring after 90 days from the completion of radiotherapy. Acute toxicity was assessed according to common toxicity criteria version $2^{(19)}$ and late toxicity was scored with the RTOG Late radiation morbidity scoring criteria ${ }^{(20)}$. Post - Treatment Assessment: On completion of therapy, patients were assessed after 6 weeks by physical and pelvic examinations, and whenever needed by abdominal ultrasonography, CT Scan, chest x-ray, cystoscopy, and proctosigmoidoscopy. Biochemical tests like complete blood count, renal function test, liver function test were also done as required. Subsequent assessments were done 12 weekly, till the completion of study period.

Response to treatment was assessed according to the Response Evaluation Criteria in Solid Tumours (RECIST) Criteria ${ }^{(21)}$.

\section{Statistical Analysis}

Data were entered and analysed using the software "Microsoft Excel 2008".

\section{Results}

A prospective randomized study to assess the feasibility of weekly Cisplatin versus Gemcitabine concomitant with radiation in the management locally advanced Carcinoma Cervix was taken up in the Department of Radiation Oncology, at a tertiary care oncology centre of eastern India. The study period was from June 2013 to May 2015.

50 patients who satisfied the eligibility criteria were enrolled for the study with 25 patients in each group. Table 1 shows that the age range of the study population was 31 to 60 years with a mean ageingroup A was $53.0( \pm 3.8)$ years and in group B was $49.0( \pm 6.5)$ years. $68 \%$ of the patient in group A and $60 \%$ patient of group B had a KPS score of 80 . Rest of the patients of both the groups had a score of 70 . 88\% patient had Antero Posterior Diameter between 
$16.1-19 \mathrm{cms}$ in both group A and group B. All the patients were of stage III B. Table 2 shows that $60 \%$ of the patients in group A and 68\% patients of group B completed external beam radiation in stipulated time as per protocol. $88 \%$ patients took $4-5$ cycles of gemcitabine and $96 \%$ patients took 4-5 cycles of cisplatin. $52 \%$ patients of group A and $60 \%$ of group B completed the overall treatment in less than 55 days. Acute toxicities were responsible for $20 \%$ of the delay in-group A and $16 \%$ of group B. Table 3 shows the acute toxicities among the patients in both the groups. All the late toxicities were mild to moderate. Table 4 shows the occurrences of late toxicities in both groups. Grade 2 skin toxicity was $4.34 \%$ in group A and $8.7 \%$ in group B. Grade 2 subcutaneous tissue toxicity in the form of fibrosis was seen in $8.7 \%$ in both the groups. No grade 2 intestinal toxicity was seen in either group. Grade 1bladder toxicity was seen in $2(8.69 \%)$ patients ingroup B. There was no any type of grade 3 or 4 late toxicity. Overall complete response was seen in $83.33 \%$ of the patients of group A and $80 \%$ patients of group B (Table 5). At the completion of the study period loco regional control was seen in $79.2 \%$ of the patients of group A and $76 \%$ of patients of group B. Locoregional failure was seen in $12.5 \%$ patients of group A and 12\% patients of group B. Distant metastases were seen in $4.17 \%$ patients of group A and $8 \%$ patients of group B.

Table 1: Distribution of study participants according to pre-treatment profile:

\begin{tabular}{|c|c|c|c|}
\hline & & $\begin{array}{c}\text { Group A } \\
(\mathrm{n}=25) \\
\text { No }(\%)\end{array}$ & $\begin{array}{c}\text { Group B } \\
(\mathrm{n}=25) \\
\text { No }(\%)\end{array}$ \\
\hline \multirow{3}{*}{$\begin{array}{l}\text { Age } \\
\text { (in years) }\end{array}$} & $31-40$ & $5(20.0)$ & $4(16.0)$ \\
\hline & $41-50$ & $14(56.0)$ & $13(52.0)$ \\
\hline & $51-60$ & $6(24.0)$ & $8(32.0)$ \\
\hline \multirow{2}{*}{$\begin{array}{l}\text { Performance Status } \\
\text { (KPS Score) }\end{array}$} & 70 & $8(32.0)$ & $10(40.0)$ \\
\hline & 80 & $17(68.0)$ & $15(60.0)$ \\
\hline \multirow{5}{*}{$\begin{array}{l}\text { APD } \\
\text { (in cm.) }\end{array}$} & $\leq 16$ & $2(8.0)$ & $1(4.0)$ \\
\hline & $16.1-17$ & $6(24.0)$ & $7(28.0)$ \\
\hline & $17.1-18$ & $9(36.0)$ & $7(28.0)$ \\
\hline & $18.1-19$ & $7(28.0)$ & $8(32.0)$ \\
\hline & $19.1-20$ & $1(4.0)$ & $2(8.0)$ \\
\hline \multirow{3}{*}{ Pathological Grade } & WD & $10(40.0)$ & $9(36.0)$ \\
\hline & $\mathrm{MD}$ & $12(48.0)$ & $13(52.0)$ \\
\hline & PD & $3(12.0)$ & $3(12.0)$ \\
\hline \multirow{3}{*}{$\begin{array}{l}\text { Tumor } \\
\text { Morphology }\end{array}$} & Exophytic & $15(60.0)$ & $13(52.0)$ \\
\hline & $\begin{array}{c}\text { Ulcero } \\
\text { Infiltrative }\end{array}$ & $7(28.0)$ & $4(16.0)$ \\
\hline & Endophytic & $3(12.0)$ & $8(32.0)$ \\
\hline
\end{tabular}

Table 2: Distribution of study participants according to treatment given:

\begin{tabular}{|c|c|c|c|}
\hline & & $\begin{array}{c}\text { Group A } \\
(\mathrm{n}=25) \\
\text { No }(\%)\end{array}$ & $\begin{array}{c}\text { Group B } \\
(\mathrm{n}=25) \\
\text { No }(\%)\end{array}$ \\
\hline \multirow{4}{*}{$\begin{array}{l}\text { EBRT } \\
\text { Treatment (in } \\
\text { days) }\end{array}$} & $<35$ as per protocol & $15(60.0)$ & $17(68.0)$ \\
\hline & $36-38$ & $7(28.0)$ & $6(24.0)$ \\
\hline & $39-41$ & $3(12.0)$ & $2(8.0)$ \\
\hline & Did not complete & $0(0.0)$ & $0(0.0)$ \\
\hline \multirow{3}{*}{$\begin{array}{l}\text { Chemotherapy } \\
\text { (No of Cycles) }\end{array}$} & 3 & $3(12.0)$ & $1(4.0)$ \\
\hline & 4 & $8(32.0)$ & $8(32.0)$ \\
\hline & 5 & $14(56.0)$ & $16(64.0)$ \\
\hline \multirow{4}{*}{$\begin{array}{l}\text { Gap between } \\
\text { EBRT\&ICRT } \\
\text { (in days) }\end{array}$} & 3-5 days & $15(60.0)$ & $16(64.0)$ \\
\hline & 6-10 days & $7(28.0)$ & $8(32.0)$ \\
\hline & $>10$ days & $2(8.0)$ & $1(4.0)$ \\
\hline & Did not take ICRT & $1(4.0)$ & $0(0.0)$ \\
\hline \multirow{4}{*}{$\begin{array}{l}\text { Overall } \\
\text { Treatment time } \\
\text { (in days) }\end{array}$} & $\leq 55$ & $13(52.0)$ & $15(60.0)$ \\
\hline & $56-63$ & $10(40.0)$ & $9(36.0)$ \\
\hline & $>63$ & $1(4.0)$ & $1(4.0)$ \\
\hline & Did not complete & $1(4.0)$ & $0(0.0)$ \\
\hline \multirow{3}{*}{$\begin{array}{ll}\text { Reasons for } \\
\text { Treatment } \\
\text { Delay }\end{array}$} & Toxicity & $5(41.7)$ & $4(40.0)$ \\
\hline & Technical/ Holidays & $3(25.0)$ & $3(30.0)$ \\
\hline & $\begin{array}{l}\text { Personal/ } \\
\text { Unknown }\end{array}$ & $4(33.3)$ & $3(30.0)$ \\
\hline
\end{tabular}

Table 3: Distribution of study participants according to acute toxicities developed

\begin{tabular}{|c|c|c|c|}
\hline Acute toxicities: & $\begin{array}{l}\text { Grade of } \\
\text { toxicity }\end{array}$ & $\begin{array}{c}\text { Group A } \\
(\mathrm{n}=25) \\
\text { No }(\%)\end{array}$ & $\begin{array}{c}\text { Group B } \\
(\mathrm{n}=25) \\
\text { No }(\%)\end{array}$ \\
\hline \multirow[t]{5}{*}{ Nausea } & 0 & $3(12.0)$ & $2(8.0)$ \\
\hline & 1 & $12(48.0)$ & $7(28.0)$ \\
\hline & 2 & $10(40.0)$ & $13(52.0)$ \\
\hline & 3 & $0(0.0)$ & $3(12.0)$ \\
\hline & 4 & $0(0.0)$ & $0(0.0)$ \\
\hline \multirow[t]{5}{*}{ Vomiting } & 0 & $3(12.0)$ & $0(0.0)$ \\
\hline & 1 & $12(48.0)$ & $9(36.0)$ \\
\hline & 2 & $9(36.0)$ & $13(52.0)$ \\
\hline & 3 & $1(4.0)$ & $3(12.0)$ \\
\hline & 4 & $0(0.0)$ & $0(0.0)$ \\
\hline \multirow[t]{5}{*}{ Diarrhoea } & 0 & $3(12.0)$ & $2(8.0)$ \\
\hline & 1 & $8(32.0)$ & $6(24.0)$ \\
\hline & 2 & $11(44.0)$ & $13(52.0)$ \\
\hline & 3 & $3(12.0)$ & $4(16.0)$ \\
\hline & 4 & $0(0.0)$ & $0(0.0)$ \\
\hline \multirow[t]{5}{*}{ Dysuria } & 0 & $10(40.0)$ & $6(24.0)$ \\
\hline & 1 & $11(44.0)$ & $13(52.0)$ \\
\hline & 2 & $4(16.0)$ & $6(24.0)$ \\
\hline & 3 & $0(0.0)$ & $0(0.0)$ \\
\hline & 4 & $0(0.0)$ & $0(0.0)$ \\
\hline \multirow{5}{*}{$\begin{array}{l}\text { Frequency of } \\
\text { Micturition }\end{array}$} & 0 & $11(44.0)$ & $8(32.0)$ \\
\hline & 1 & $10(40.0)$ & $12(48.0)$ \\
\hline & 2 & $4(16.0)$ & $5(20.0)$ \\
\hline & 3 & $0(0.0)$ & $0(0.0)$ \\
\hline & 4 & $0(0.0)$ & $0(0.0)$ \\
\hline \multirow[t]{5}{*}{ Anemia } & 0 & $10(40.0)$ & $10(40.0)$ \\
\hline & 1 & $11(44.0)$ & $13(52.0)$ \\
\hline & 2 & $4(16.0)$ & $2(8.0)$ \\
\hline & 3 & $0(0.0)$ & $0(0.0)$ \\
\hline & 4 & $0(0.0)$ & $0(0.0)$ \\
\hline \multirow[t]{5}{*}{ Leucopenia } & 0 & $6(24.0)$ & $9(36.0)$ \\
\hline & 1 & $14(56.0)$ & $13(52.0)$ \\
\hline & 2 & $5(20.0)$ & $3(12.0)$ \\
\hline & 3 & $0(0.0)$ & $0(0.0)$ \\
\hline & 4 & $0(0.0)$ & $0(0.0)$ \\
\hline \multirow[t]{5}{*}{ Thrombocytopenia } & 0 & $23(92.0)$ & $24(96.0)$ \\
\hline & 1 & $2(8.0)$ & $1(4.0)$ \\
\hline & 2 & $0(0.0)$ & $0(0.0)$ \\
\hline & 3 & $0(0.0)$ & $0(0.0)$ \\
\hline & 4 & $0(0.0)$ & $0(0.0)$ \\
\hline Radiation & 0 & $0(0.0)$ & $0(0.0)$ \\
\hline
\end{tabular}




\begin{tabular}{|l|c|c|c|}
\hline Dermatitis & 1 & $22(88.0)$ & $21(84.0)$ \\
\cline { 2 - 4 } & 2 & $3(12.0)$ & $4(16.0)$ \\
\cline { 2 - 4 } & 3 & $0(0.0)$ & $0(0.0)$ \\
\cline { 2 - 4 } & 4 & $0(0.0)$ & $0(0.0)$ \\
\hline Serum Creatinine & 0 & $25(100.0)$ & $23(92.0)$ \\
\cline { 2 - 4 } & 1 & $0(0.0)$ & $2(8.0)$ \\
\cline { 2 - 4 } & 2 & $0(0.0)$ & $0(0.0)$ \\
\cline { 2 - 4 } & 3 & $0(0.0)$ & $0(0.0)$ \\
\cline { 2 - 4 } & 4 & $0(0.0)$ & $0(0.0)$ \\
\hline
\end{tabular}

Table 4: Distribution of study participants according to late toxicities developed

\begin{tabular}{|c|c|c|c|}
\hline Late toxicities: & $\begin{array}{l}\text { Grade of } \\
\text { toxicity }\end{array}$ & $\begin{array}{c}\text { Group A } \\
(\mathrm{n}=25) \\
\text { No }(\%)\end{array}$ & $\begin{array}{c}\text { Group B } \\
(\mathrm{n}=25) \\
\text { No }(\%)\end{array}$ \\
\hline \multirow[t]{5}{*}{ Late skin Toxicities } & 0 & $0(0.0)$ & $0(0.0)$ \\
\hline & 1 & $22(95.6)$ & $21(91.3)$ \\
\hline & 2 & $1(4.3)$ & $2(8.7)$ \\
\hline & 3 & $0(0.0)$ & $0(0.0)$ \\
\hline & 4 & $0(0.0)$ & $0(0.0)$ \\
\hline \multirow{5}{*}{$\begin{array}{ll}\text { Sub-Cutaneous } & \text { tissue } \\
\text { Toxicities } & \\
\text { [Fibrosis] } & \end{array}$} & 0 & $7(30.4)$ & $8(34.8)$ \\
\hline & 1 & $14(60.8)$ & $13(56.5)$ \\
\hline & 2 & $2(8.7)$ & $2(8.7)$ \\
\hline & 3 & $0(0.0)$ & $0(0.0)$ \\
\hline & 4 & $0(0.0)$ & $0(0.0)$ \\
\hline \multirow{5}{*}{$\begin{array}{l}\text { Small/ Large Intestine } \\
\text { Toxicities } \\
\text { [Diarrhoea/Cramps] }\end{array}$} & 0 & $8(34.8)$ & $7(30.4)$ \\
\hline & 1 & $15(65.2)$ & $16(69.6)$ \\
\hline & 2 & $0(0.0)$ & $0(0.0)$ \\
\hline & 3 & $0(0.0)$ & $0(0.0)$ \\
\hline & 4 & $0(0.0)$ & $0(0.0)$ \\
\hline \multirow{5}{*}{$\begin{array}{l}\text { Bladder Toxicities } \\
\text { [Haematuria, Dysuria] }\end{array}$} & 0 & $20(86.9)$ & $17(73.9)$ \\
\hline & 1 & $3(13.0)$ & $4(17.4)$ \\
\hline & 2 & $0(0.0)$ & $2(8.7)$ \\
\hline & 3 & $0(0.0)$ & $0(0.0)$ \\
\hline & 4 & $0(0.0)$ & $0(0.0)$ \\
\hline \multirow{5}{*}{$\begin{array}{l}\text { Kidney Toxicities } \\
\text { [Serum Creatinine] }\end{array}$} & 0 & $23(100.0)$ & $21(91.3)$ \\
\hline & 1 & $0(0.0)$ & $2(8.7)$ \\
\hline & 2 & $0(0.0)$ & $0(0.0)$ \\
\hline & 3 & $0(0.0)$ & $0(0.0)$ \\
\hline & 4 & $0(0.0)$ & $0(0.0)$ \\
\hline
\end{tabular}

Table 5: Distribution of study participants according to late toxicities developed among the study participants:

\begin{tabular}{|l|c|c|c|}
\hline & & $\begin{array}{c}\text { Group A } \\
(\mathrm{n}=25) \\
\text { No }(\%)\end{array}$ & $\begin{array}{c}\text { Group B } \\
(\mathrm{n}=25) \\
\text { No }(\%)\end{array}$ \\
\hline $\begin{array}{l}\text { Response at first } \\
\text { follow up[After 6 } \\
\text { weeks] }\end{array}$ & $\mathrm{CR}$ & $20(83.3)$ & $20(80.0)$ \\
\cline { 2 - 4 } & $\mathrm{PR}$ & $4(16.7)$ & $5(20.0)$ \\
\cline { 2 - 4 } & $\mathrm{SD}$ & $0(0.0)$ & $0(0.0)$ \\
\hline \multirow{2}{*}{$\begin{array}{l}\text { Response at 12 } \\
\text { month of median } \\
\text { follow up }\end{array}$} & PD & $0(0.0)$ & $0(0.0)$ \\
\cline { 2 - 4 } & LRF & $19(79.2)$ & $19(76.0)$ \\
\cline { 2 - 4 } & DM & $1(4.2)$ & $3(12.0)$ \\
\cline { 2 - 4 } & LFU & $1(4.2)$ & $1(4.0)$ \\
\cline { 2 - 4 } & Death & $0(0.0)$ & $0(0.0)$ \\
\hline
\end{tabular}

CR-Compete Response; PR-Partial Response; SD- Stable Disease; PDProgressive disease; LRC- Loco regional Control; LRF- Loco regional failure; DM-Distant Metastasis; LFU-Lost to follow-up.

\section{Discussion}

The study has been conducted in Department of Radiation Oncology, at a tertiarty care oncology center of eastern india. The study period was from June 2013 to May 2015. Total of 50 patients who satisfied the eligibility criteria where enrolled to the study. These patients were randomized with 25 patients in Gemcitabine armas study group (A) and 25 patients in the Cisplatin arm as the control group (B).

The age of the patients ranged from 31-60 years with a mean age ( \pm S.D) in-group A was $53.0( \pm 3.8)$ years and in-group B was $49.0( \pm 6.5)$ years. The majority of patients were above 45 years. This is in accordance with data from cancer registries in developing countries, which suggest that about $80 \%$ - 90\% of confirmed cervical cancer cases occur among women age 35 or older. The incidence of cancer in most countries is very low in women under age 25 while incidence increases at about ages 35 to 40 and reaches a maximum in their 50 s and $60 \mathrm{~s}^{(1)}$ mainly because of slow progression of cervical cancers from pre-cancerous lesions to advanced cancer.

In our study $68 \%$ patient in group A and $60 \%$ in group B had Karnofsky Performance Status of 80 and the rest had a Karnofsky Performance Status of 70 in either group. Similar pattern was also seen in study by Arun K et al. ${ }^{(15)}$ where more number of patients had Karnofsky Performace Status of 80 or more.

Moderately differentiated Squamous Cell Carcinoma was predominant in both groups. Rose PG et al ${ }^{(16)}$ had similar results with $60.8 \%$ of patients having Moderately differentiated Squamous cell carcinoma.

In our study External Beam Radiotherapy (EBRT) was deliverd by AP-PA, Parallel opposed field using cobalt - 60 (Gamma Rays) with SAD technique. Each patient received 50 gy in 25 fractions at a dose of $2 \mathrm{gy} /$ fraction, in five weeks duration. $60 \%$ patientsin-group A completed their External Beam Radiotherapy in stipulated time. Kundu et al ${ }^{(24)}$ had similar EBRT delivery technique, total dose and dose fractionation.

In our study all patient received gemcitabine $(150 \mathrm{mg} / \mathrm{m} 2)$ in group A and cisplatin $40 \mathrm{mg} / \mathrm{m} 2$ in group B concurrent with EBRT weekly. Cisplatin in control arm is used as standard of care, on the basis of the Randomised trials with enthusiastic results ${ }^{(4,5)}$. 
Gemcitabine which is used in study arm has been shown to be a potent Radiosensitizer in cervical cell line ${ }^{(7)}$. Gemcitabine has shown promising radio sensitising effect in preclinical as well as in clinical phase II trials. There are three Phase II trials using gemcitabine alone or in combination with cisplatin concurrently with radiation showing good results ${ }^{(8)}$. $88 \%$ patients took $4-5$ cycles of gemcitabine and $96 \%$ patient took 4-5 cycles of cisplatin. This observation is similar to the results of the trial by E.P Saibishkumar et al. (18) in which concomitant cisplatin was administered with pelvic radiotherapy. There is a delay in delivery of chemotheraphy cycles, reduction in number of chemotherapy cyles and prolongation of EBRT treatment time in cisplatin and gemcitabine group. These delays can compromise the survival functions in further follow up. Financial constraints and toxicity was an important cause for the difference in the number of cycles taken by the patients in either of the groups. The gap between EBRT and ICRT was 3-13 days in group A and 3-11 days in group B. The estimated overall time was $\leq 55$ days. In our study ICRT was given by HDR brachytherapy with Iridium-192 as the source. Hareyama et al. ${ }^{(19)}$ studied the results of 132 patients treated with LDR brachytherapy or HDR brachytherapy in stage II and IIIB carcinoma cervix and reported 5 year disease specific survival for LDR vs HDR brachytherapy for stage II was $87 \%$ and $69 \%$ respectively and for stage IIIB $60 \%$ vs $51 \%$ respectively. We gave three applications of 600$700 c G y$ each to point A one week apart. 52\% patients completed treatment in stipulated time in group A \& 60\% in group B. Rest patients completed their treatment in less than 65 days. Similar results were seen in study done by Chufal et al. ${ }^{(20)}$ where the overall treatment time required in gemcitabine group was more than that in cisplatin group. The treatment delay in-group A of 12 patients were due to various reasons. Among them acute toxicity was the main cause. In our study acute toxicity was mostly gastrointestinal followed by haematological. In group A. $16 \%$ patient developed grade 2 anemia vs. $8 \%$ in group B. $20 \%$ grade 2 Leucopenia was observed in group A and $12 \%$ in group B, which was comparable to the study done by Chufal et al
(20). The study had grade $2 / 3$ leucopenia of $18 \%$ and $15.6 \%$ in gemcitabine and cisplatin arm respectively. In the study, by Arun et al. ${ }^{(15)}$ grade 3 lucopenia was observed in one patient receiving gemcitabine. No grade 3 leucopenia was found in cisplatin arm. In our study grade 2 Leucopenia, could be managed by growth factors (G-CSF). Grade 1 thrombocytopenia was seen in $8 \%$ and $4 \%$ patients in group $\mathrm{A}$ and group B respectively in our study. This was comparable with the study by Arun $\mathrm{K}$ et al ${ }^{(15)}$ in which grade 1 thrombocytopenia was $2 / 20$ vs $0 / 16$ in gemcitabine and cisplatine arm respectively. Probably low economic condition resulting in poor general condition of cervical cancer patients in our country is the cause of high incidence of anemia and other haematological toxicities met in the present study. Grade 2 dermatitis was more in cisplatin group $16 \%$ vs. $12 \%$ in gemcitabine group and is similar to the study done by Arun k et al ${ }^{(15)}$. Grade 3 toxicity was not seen in our study as evident in study by Bhatt et al ${ }^{(9)}$. Nausea \& vomiting was more common in cisplatin arm as compared to gemcitabine with grade 3 toxicity of $12 \%$ Vs $4 \%$ respectively. Similar toxicity profile was seen in Chufal et al study ${ }^{(20)}$ with $10 \%$ \& $6 \%$ in cisplatin\& gemcitabine respectively. Cisplatin is more emetogenic than gemcitabine. Using antiemetic agents can ensure adequate prevention of nausea and vomiting. Diarrhoea was the main cause of hospitalization in patients in both arms. Grade 3 diarrhoea was seen more in cisplatin arm.(16\% vs $12 \%)$ when compared to gemcitabine arm. Similar to study by Chufal et at ${ }^{(20)}$. Bhatt et al ${ }^{(9)}$ reported grade 3 diarrhoea in gemcitabine group as compared to cisplatin (14\% vs $3 \%$ ). Pattaranupaporn et al. ${ }^{(8)}$ reported only 1 cases of grade 3 diarrhoea out of 19 patients receiving gemcitabine. Diarrhoea was the most common cause of toxicity in our patients. Repeated pelvic infection of our woman particularly from rural areas, leading to adherence of gut to the lower pelvis may be the cause of this diarrhoea. Renal toxicity in the form of serum creatinine, Dysuria and frequency of micturition was more common in-group B patient. Most of the toxicities can be treated on outpatient basis thus minimizing the cost of patient management. Both the factors are 
very important in developing country like our, with a huge number of cervical cancer patients mostly in advanced stage. $83 \%$ complete response was observed in gemcitabine and $80 \%$ in cisplatin arm after 6 weeks of completion of treatment. Bhatt et al ${ }^{(9)}$ in his study had complete response $89 \%$ vs $72 \%$ in gemcitabine and cisplatin arm respectively. Pattaranutapar et al ${ }^{(8)}$ reported $89.5 \%$ complete response and $5.25 \%$ partial response. No response was seen in one patient. The higher response rate was due to the use of gemcitabine with the dose of $300 \mathrm{mg} / \mathrm{m} 2$. Thus, more dose of gemcitabine in this study must have increased the antitumor activity. This was converted into a higher complete response. Late toxicity was evaluated after a median follow up of 12 months ranging from 6-18 months. Grade 2skin toxicity was observed more in cisplatin arm. Grade 2-subcutanous fibrosis was similar in both the arms. There were no significant differences in toxicity of small/large intestine, with patients complaining of mild diarrhoea and cramps. Grade 2bladder toxicity was seen in 2 patients having intermittent haematuria in cisplatin group. Grade I Renal toxicity was seen in 2 patients in cisplatin arm with serum creatinine level between 1.5 $2 \mathrm{mg} \%$. Cisplatin is a nephrotoxic drug and this toxicity is of concern in patients population that harbor renal dysfunction. The study done by Cetina et al (21) showed high activity and tolerability of gemcitabine during radiation in patients suffering from cervical tumor causing obstruction of ureter, thus causing renal dysfunction. According to the above study(21), eight cervical carcinoma patients whose serum creatinine ranged from 1.6-18.5 $\mathrm{mg} / 100 \mathrm{~mL}$ (median, 3.3; mean, 6.8) received gemcitabine at $300 \mathrm{mg} / \mathrm{m} 2$ concurrent with standard pelvic radiation. Despite the fact that the majority of patients had grade 3 leukopenia and neutropenia, dermatitis, colitis, and proctitis, eight of nine (89\%) patients achieved complete response and all exhibited improvement in creatinine clearance (pretherapy, 22.78; post-therapy, $54.3 \mathrm{mg} / \mathrm{ml} / \mathrm{min})(\mathrm{p}=$ 0.0058 ) and all but one normalized serum creatinine. At a median follow-up of 11 months (range, 6-14 months), all patients are alive, one with pelvic and another with systemic disease. Thus, cervical tumorsupto pelvic wall causing obstruction of ureter (renal insufficiency) should not be a contra indication for receiving chemoradiation to attempt a cure. In this setting in which cisplatin is contraindicated; gemcitabine use should be considered ${ }^{(21)}$. In our study, after 12 months of median follow up (range 6-18months) the locoreginal control was $79.16 \%$ in gemcitabine arm and $76 \%$ in cisplatin arm. Response at first follow up (6 weeks) after treatment was a significant factor in influencing disease control on further follow up. There was similar loco-regional control in both arms. Patient with complete response had no relapse in both the groups. Complete response rates seen were inferior to that achieved by Pattaranutaporn et al. ${ }^{(8)}(89.5 \%)$. The cause of our lower response rates compared to other studies may be high doses of gemcitabine and addition of lower stage disease IB2 and more number of cases with stage IIA. Loco regional failure was almost equal $12.5 \%$ \& $12 \%$ ingroup A \& group B in our study. Pelvic failure rate corresponds to as reported by Pataranutaporn et al $(11 \%)^{(8)}$. In our study, distant metastasis was $1(4 \%)$ and $2(8 \%)$ in group A and group B respectively. Distant failure corresponds to as repoted by Pataranutporn et al 5\% ${ }^{(8)}$ and Cetina et al $12 \%^{(21)}$. One patient in-group B had supra-clavicular lymph node as the site of metastasis. The lower distant failure rate may be attributed to the addition of gemcitabine to Radiotherapy. Probably micro metastasis was countered by gemcitabine. This needs to be considered in future studies. One patient in each group was lost to follow up.

In our scenario, patients were illiterate and generally belong to low socio-economic group and long-term follow up was difficult. Gemcitabine was easily administered, well tolerated with good compliance to concurrent chemoradiation. Weekly gemcitabine concomitant with radiation had similar disease control and tolerable toxicity profile when compared with cisplatin. Gemcitabine can be a viable option as alternative to cisplatin in patients with renal dysfunction where cisplatin is contraindicated due to renal compromise. 


\section{References}

1. Ferlay J, Soerjomataram I, Ervik M, Dikshit R, Eser S, Mathers C, et al. (2013). GLOBOCAN 2012 v1.0, Cancer Incidence and Mortality Worldwide.

2. WHO/ICO Information Centre on HPV and Cervical Cancer (HPV Information Centre). Summary report on HPV and cervical cancer statistics in India 2007. Available from: http://www.who.int/hpvcentre.

3. Miller AB: Cervical cancer screening programmes: managerial guidelines. Geneva: World Health Organisation; 1992.

4. Rose PG, Bundy BN, Watkins EB, Thigpen JT, Deppe G, Maiman MA, et al. Concurrent cisplatin-based radiotherapy and chemotherapy for locally advanced cervical cancer. N Engl J Med 1999; 340:1144-1153.

5. Whitney CW, Sause W, Bundy BN, Malfetano JH, Hannigan EV,Fowler WC Jr, et al. Randomized comparison of fluorouracil plus cisplatin versus hydroxyurea as an adjunct to radiation therapy in stage IIB-IVA carcinoma of the cervix with negative para-aortic lymph nodes: A Gynecologic Oncology Group and Southwest Oncology Group study. J ClinOncol. 1999; 17:1339-1348.

6. Lawrence TS, Eisbruch A, Shewach DS. Gemcitabine-mediated radiosensitization. SeminOncol.1997; 24:24-28.

7. Hernández P, Olivera P, Dueñas-Gonzalez A, Perez-Pastenes MA, Zarate A, Maldonado V, et al. Gemcitabine activity in cervical cancer cell lines. Cancer Chemother Pharmacol 2001; 48:488-492.

8. Pattaranutaporn $\mathrm{P}$, Thirapakawong C, Chansilpa Y, Thersakvivhya S, Ieumwananontachai N, Thephamongkhol K. Phase II study of concurrent gemcitabine and radiotherapy in locally advanced stage IIIB cervical carcinoma.GynecolOncol. 2001;81:404-407.

9. Bhatt ML, Matin A, Srivastava M, Pant MC, Srivastava K,Gupta S, et al . Journal of
Clinical oncology. 2007 ASCO Annual Meeting proceedings part I $\mathrm{Vol}$.

10. Devita, Hellman, and Rosenberg's Cancer Principles and Practice of oncology.Wolter Kluwer; 9th ed. 2011:1315 .

11. Anthony Fauci., Eugene Braunwald., Dennis Kasper., Stephen Hauser., Dan Longo., J. Jameson. et al. Harrison's principles of internal medicine. McGraw-Hill Education; Vol 2, 19th ed. 2016:472

12. Cooperative Group Common Toxicity Criteria [Internet]. Rtog.org. 2017 [cited 4 June 2017]. Available from: https://www.rtog.org/ResearchAssociates/A dverseEventReporting/CooperativeGroupCo mmonToxicityCriteria.aspx

13. RTOG/EORTC Late Radiation Morbidity Scoring Schema [Internet]. Rtog.org. 2017 [cited 4 June 2017]. Available from: https://www.rtog.org/ResearchAssociates/A dverseEventReporting/RTOGEORTCLateR adiationMorbidityScoringSchema.aspx

14. Eisenhauer E, Therasse P, Bogaerts J, Schwartz L, Sargent D, Ford R et al. New response evaluation criteria in solid tumours: Revised RECIST guideline (version 1.1). European Journal of Cancer. 2009;45(2):228-247.

15. Verma AK, Arya AK, Kumar M, Kumar A, Gupta S, RathG.k. et al. Weekly cisplatin or gemcitabine concomitant with radiation in the management of locally advanced carcinoma cervix: results from an observational study. J GynecolOncol. Dec.2009; 20[4]:221-226.

16. Rose PG, Ali S, WhitneyCW, Lanciano R, Stehman FB. Outcome of stage IVA cervical cancer patients with disease limited to pelvis in the era of chemoradiation.Gynecooncol 2011;121:542-45.

17. Kundu S, Basu S, Acharya, S, Dastidar AG, Roy A. Chemoradiation in Locally advanced cervical cancer : a randomized trial. Indian J of Med \&PediaOncol. 2008; 29(4).

18. Elantholi P. Saibishkumar, Firuza D. Patel, Suresh C. Sharma . Results of a phase II 
trial of concurrent chemoradiation in the treatment of locally advanced carcinoma of uterine cervix: an experience from India. Bull Cancer. 2005 ; 92 (1) : E7-12.

19. HareyamaH,SakataK,OouchiA,NagakuraH,S hidoM,Someya M. High-Dose-Rate versus Low-Dose-Rate Intracavitary Therapy For Carcinoma of the Uterine Cervix.Cancer; 94:117-124.

20. Chufal KS, Rastogi M, Srivastava M, Pant MC, Bhatt MLB, Srivastava K. concurrent chomoradiotherapy for locally advanced cervical cancer using Gemcitabine : non randomized comparison of three sequential protocols. Cancer Therapy. 2007;5:43-54.

21. Cetina L, Rivera L, Candelaria M, de la Garza J, Duenas-Gonzalez A. Chemoradiation with gemcitabine for cervical cancer in patients with renal failure. Anticancer Drugs2004; 15:761-766. 